\title{
Age and Gender Differences in Cytokine Profile of Lymph and Blood Serum
}

\author{
Alexandr Poveshchenko*, Nikolai Orlov, Oleg Kazakov, Olga Poveshchenko, Irina Kim, \\ Natali Bondarenko, Tatjana Miller, Dmitri Strunkin, Alexei Kabakov, Tatjana Reiter, \\ Vladimir Konenkov
}

FSBI Scientific Institution of Clinical and Experimental Lymphology SB RAMS, Novosibirsk, Russia Email: ${ }^{*}$ poveshchenkoa200@mail.ru

Received 19 May 2014; revised 20 June 2014; accepted 3 July 2014

Copyright (C) 2014 by authors and Scientific Research Publishing Inc.

This work is licensed under the Creative Commons Attribution International License (CC BY). http://creativecommons.org/licenses/by/4.0/

(c) (7) Open Access

\begin{abstract}
We studied the cytokine profile (IL-1 $\alpha$, IL-1 $\beta$, IL-2, IL-4, IL-6, IL-10, GM-CSF, interferon- $\gamma$, TNF $\alpha$,) of the lymph, blood serum and conditioned medium of the lymph cells of Wistar rats. It was found that the concentration of cytokines investigated in the lymph of Wistar rats was significantly higher compared to the serum. Age and gender differences between the concentration of pro- and anti-inflammatory cytokines in the lymph and blood serum were found. The concentration of the cytokines was determined using the test system "Bio-Rad".
\end{abstract}

\section{Keywords}

Cytokines, Lymph, Blood Serum

\section{Introduction}

Cytokines are a system that regulates the function of the organism, ensures the development of protective responses and maintains homeostasis under different impact sequences. At present, the important role of cytokines is found in such things as factors of the internal environment of the body under normal conditions at different stages of ontogeny of the organism in the development of socially significant diseases, assisting such things as removal of doubt in prognostic factors. The concept of the functional activity of immune cells is associated with parameters such as the capacity for intercellular interactions, the level of proliferation and degree of differentiation, and the ability of the active secretion (cytokines, immunoglobulins, and histocompatibility antigens) [1]. According to recent studies, cytokines can be allocated to the new system of self-regulation of body functions, which exists along with the nervous and hormonal regulation [2]. They are distinguished from hormones in which they are synthesized and secreted by a variety of cell types that, accordingly, control all their diversity.

${ }^{*}$ Corresponding author.

How to cite this paper: Poveshchenko, A., et al. (2014) Age and Gender Differences in Cytokine Profile of Lymph and Blood Serum. Advances in Aging Research, 3, 216-221. http://dx.doi.org/10.4236/aar.2014.33030 
They have not only endocrine but pronounced autocrine and paracrine activity. The universality of cytokines is the ability to show the biological activity of both distant and intercellular contacts. Synthesizing the inflammation, cytokines affect virtually all cells involved in inflammation. In the case of the failure of local reactions, protective cytokines enter the circulation; their activity is manifested at the systemic level, leading to the development of acute phase response at the body. Cytokines, as factors of lymphoid systems, play an important role in the ontogeny of the body at different stages. Cytokine profiles of the lymph have remained largely unexplored, despite the fact that the lymph is the most important part of the internal environment of the body.

Objective: To quantify the characteristics and features of the cytokine profile of the blood and lymph circulation at different stages of ontogeny: a comparative study of cytokines in the lymph and blood of Wistar rats in the infantile ( 3 months) and middle age (9 months) periods; also, to examine the gender-specific cytokine profile of the lymph.

\section{Materials and Methods}

The experiment was performed on rats: male and female Wistar rats weighing $150-200 \mathrm{~g}$ in a quantity of 9 - 10 animals in each study group. The animals were housed in standard vivarium conditions, with free access to food and water. Work with animals was conducted in accordance with the "Rules of the work on experimental animals." The experiment on the animals was performed at the same time in the morning. Lymph was collected from the thoracic duct [3]. Cells were isolated from the lymph precipitate after centrifugation lymph was cultured for 72 hours in a culture medium RPMI-1640, supplemented with $10 \%$ fetal calf serum (FCS; Biolot, Russia ), $160 \mu \mathrm{g} / \mathrm{ml}$ gentamycin sulfate ( Dalkhimpharm, Russia ), $2 \mathrm{mM}$ L-glutamine (ICN, USA) in a $\mathrm{CO}_{2}$ incubator at $37^{\circ} \mathrm{C}$ and $5 \% \mathrm{CO}_{2}$. After incubating in the collected conditioned environment (COP), it was dispensed into aliquots and stored at $-70^{\circ} \mathrm{C}$ until use.

To investigate the cytokine concentrations in the conditioned medium of the lymph, serum and lymph cells, a test system was used (Bio-Plex Pro Rat Cytokoness 9-Plex Assay, Bio-Rad, USA). The concentration of the cytokines was expressed in picograms $/ \mathrm{ml}$.

Statistical analysis was performed with the use of Excel 2000 and Statistica 8.0. Because of the small sample size to test the hypothesis of the presence or absence of differences between the experimental and control groups of animals using the Mann-Whitney test (Me; LQ-HQ), differences between groups were considered significant at $\mathrm{p}<0.05$.

\section{Results}

In the study of cytokine concentrations in the serum of three males at 9 months of age it was revealed that the content of IL- $1 \beta$ was significantly higher in males aged 3 months. The concentration of pro-inflammatory cytokine IL- $1 \alpha$ and IL- $1 \beta$ in the serum of females of 9 months is higher compared with males of the same age. The content of IL-10 in the serum of males aged 3 months and above compared to males aged 9 months, while the content of IL-4 in the serum of males aged 9 months (Table 1). In the study of cytokine in the serum of males and females aged 9 months it was found that the content of pro-inflammatory cytokines IL- $1 \alpha$ and IL- $1 \beta$ was significantly higher in females. The concentration of the anti-inflammatory cytokine IL-10 in the serum is also higher in females of 9 months, with IL-4 being higher in males of the same age (Table 2). In the study of cytokine concentrations in the lymph, for males of 3 months of age there was found less IL- $1 \alpha$ and more GM-CSF than the levels in the lymph in males aged 9 months (Table 3). In the lymph of females aged 9 months there was significantly less IL-1 $\alpha$ compared with males of the same age (Table 4), wherein the conditioned medium of cells in lymph females also contained significantly less IL-1 $\alpha$ than the conditioned medium of males and $6.0 \pm$ $2.2,12.2 \pm 5.1$ respectively $(\mathrm{p}=0.015)$. A comparative study of cytokine concentrations in the lymph and blood serum showed higher lymph cytokines content compared with the serum (Tables 5-7).

\section{Discussion}

It is known that with age there often appears dysregulation of the immune function, leading to a decline in health and increased sensitivity to various diseases. Studies of cytokine profiles of lymph and blood serum are conducted to identify markers of aging. The results obtained by different researchers found an increased production of pro-inflammatory cytokines such as IL- $1 \alpha$ and IL-1 $\beta$, IL-6 in the group of older animals [4] but we have not 
Table 1. The concentration of cytokine in the blood serum of males of 3 and 9 months of age.

\begin{tabular}{cccccc}
\hline Group of animals & $\begin{array}{c}\text { Concentration of cytokine in blood serum of } \\
\text { males of three months of age }\end{array}$ & $\begin{array}{c}\text { Concentration of cytokine in blood serum of } \\
\text { males of nine months of age }\end{array}$ \\
\hline cytokines & $\mathrm{M} \pm \sigma$ & $\mathrm{Me}$; (LQ-HQ) & $\mathrm{M} \pm \sigma$ & $\mathrm{Me}$ (LQ-HQ) & $\mathrm{p}$ \\
IL-1 $\alpha$ & $4.3 \pm 1.7$ & $4.6 ;(3.3-6.4)$ & $3.6 \pm 1.8$ & $3.6 ;(1.8-5.0)$ & 0.49 \\
IL-1 $\beta$ & $27.8 \pm 13.4$ & $27.8 ;(14.3-41.2)$ & $2.8 \pm 1.4$ & $2.2 ;(1.8-3.5)$ & 0.0007 \\
IL-2 & $2.5 \pm 1.1$ & $2.1 ;(1.8-3.4)$ & $2.3 \pm 0.8$ & $2.1 ;(1.8-2.4)$ & 0.87 \\
IL-4 & $5.7 \pm 0.8$ & $6.4 ;(4.6-6.4)$ & $9.4 \pm 3.0$ & $9.4 ;(6.4-12.4)$ & 0.02 \\
IL-6 & $2.8 \pm 1.2$ & $2.6 ;(1.8-4.1)$ & $3.1 \pm 1.2$ & $2.6 ;(2.1-3.5)$ & 0.83 \\
IL-10 & $259.2 \pm 152.6$ & $259.2 ;(106.6-411.9)$ & $59.0 \pm 16.8$ & $59.0 ;(42.2-75.8)$ & 0.0007 \\
GM-CSF & $2.9 \pm 1.6$ & $2.6 ;(1.0-4.1)$ & $2.6 \pm 1.3$ & $2.6 ;(1.0-4.1)$ & 0.8 \\
IFN $\gamma$ & $3.1 \pm 1.5$ & $2.8 ;(1.8-4.2)$ & $3.7 \pm 2.1$ & $3.6 ;(1.1-6.4)$ & 0.59 \\
TNF $\alpha$ & $3.1 \pm 1.5$ & $2.7 ;(1.8-4.3)$ & $4.3 \pm 1.7$ & $4.4 ;(2.9-6.4)$ & 0.24 \\
\hline
\end{tabular}

Table 2. The concentration of cytokine in the blood serum of males and females aged 9 months.

\begin{tabular}{|c|c|c|c|c|c|}
\hline \multirow{2}{*}{$\begin{array}{c}\text { Group of animals } \\
\text { cytokines }\end{array}$} & \multicolumn{4}{|c|}{$\begin{array}{l}\text { Concentration of cytokine in the blood serum Concentration of cytokine in the blood serum } \\
\text { of females of nine months of age }\end{array}$} & \multirow[b]{2}{*}{$\mathrm{p}$} \\
\hline & $\mathrm{M} \pm \sigma$ & Me; (LQ-HQ) & $\mathrm{M} \pm \sigma$ & Me; (LQ-HQ) & \\
\hline IL-1 $\alpha$ & $7.4 \pm 0.8$ & $6.9 ;(6.7-7.8)$ & $3.6 \pm 1.8$ & 3.6; $(1.8-5.0)$ & 0.07 \\
\hline IL- $1 \beta$ & $50.6 \pm 4.0$ & $50.6 ;(46.6-54.6)$ & $2.8 \pm 1.4$ & $2.2 ;(1.8-3.5)$ & 0.0007 \\
\hline IL-2 & $2.7 \pm 1.2$ & $2.7 ;(1.8-3.5)$ & $2.3 \pm 0.8$ & $2.1 ;(1.8-2.4)$ & 0.4 \\
\hline IL-4 & $2.7 \pm 1.0$ & $2.2 ;(2.1-3.40)$ & $9.4 \pm 3.0$ & $9.4 ;(6.4-12.4)$ & 0.0007 \\
\hline IL-6 & $2.8 \pm 1.0$ & $2.2 ;(2.1-3.4)$ & $3.1 \pm 1.2$ & $2.6 ;(2.1-3.5)$ & 1.0 \\
\hline IL-10 & $121.2 \pm 14.6$ & 121.2; (106.6 - 135.8) & $59.0 \pm 16.8$ & 59.0; (42.2 - 75.8) & 0.0007 \\
\hline GM-CSF & $2.6 \pm 1.1$ & $2.6 ;(1.8-3.4)$ & $2.6 \pm 1.3$ & $2.6 ;(1.0-4.1)$ & 0.9 \\
\hline $\mathrm{IFN} \gamma$ & $3.4 \pm 1.5$ & $3.6 ;(1.9-4.6)$ & $3.7 \pm 2.1$ & $3.6 ;(1.1-6.4)$ & 0.7 \\
\hline TNF $\alpha$ & $3.5 \pm 1.3$ & $3.2 ;(2.1-4.3)$ & $4.3 \pm 1.7$ & $4.4 ;(2.9-6.4)$ & 0.34 \\
\hline
\end{tabular}

Table 3. Cytokine concentrations in the lymph in males aged 3 months and 9 months of age.

\begin{tabular}{|c|c|c|c|c|c|}
\hline \multirow{2}{*}{$\begin{array}{c}\text { Group of animals } \\
\text { cytokines }\end{array}$} & \multicolumn{2}{|c|}{$\begin{array}{l}\text { Concentration of cytokine in the lymph of } \\
\text { females and males of three months of age }\end{array}$} & \multicolumn{2}{|c|}{$\begin{array}{l}\text { Concentration of cytokine in the lymph of } \\
\text { males of nine months of age }\end{array}$} & \multirow[b]{2}{*}{$\mathrm{p}$} \\
\hline & $\mathrm{M} \pm \sigma$ & Me; (LQ-HQ) & $\mathrm{M} \pm \sigma$ & Me; ( LQ-HQ) & \\
\hline IL-1 $\alpha$ & $10.9 \pm 6.3$ & $10.1 ;(4.6-16.4)$ & $27.3 \pm 12.7$ & 24.9; (15.7 - 37.1) & 0.05 \\
\hline IL- $1 \beta$ & $151.2 \pm 59.1$ & 148.5; (98.8 - 200.9) & $151.7 \pm 59.6$ & 147.2; (98.2 - 202.3) & 1.0 \\
\hline IL-2 & $979.4 \pm 349.8$ & 979.5; (662.5 - 1296.4) & $722.6 \pm 580.8$ & $361.7 ;(243.5$ - 1127.6) & 0.2 \\
\hline IL-4 & $13.9 \pm 7.9$ & $18.1 ;(4.6-19.4)$ & $13.1 \pm 9.3$ & $9.5 ;(5.8-9.5)$ & 0.8 \\
\hline IL-6 & $4.2 \pm 1.6$ & $4.8 ;(3.7-5.3)$ & $4.9 \pm 1.4$ & $5.6 ;(4.7-6.4)$ & 0.4 \\
\hline IL-10 & $255.7 \pm 78.1$ & 223.7; (203.8 - 275.6) & $233.1 \pm 75.9$ & $217.2 ;(177.1$ - 283.2) & 0.5 \\
\hline GM - CSF & $51.8 \pm 43.1$ & 46.6; (10.7 - 87.8) & $10.5 \pm 4.6$ & $9.5 ;(6.1-9.5)$ & 0.05 \\
\hline $\mathrm{IFN} \gamma$ & $134.7 \pm 9.6$ & 139.6; (132.7 - 141.5) & $128.5 \pm 101.9$ & 89.2; (34.8 - 209.2) & 0.4 \\
\hline $\mathrm{TNF} \alpha$ & $2.7 \pm 1.2$ & $2.2 ;(1.9-3.5)$ & $2.7 \pm 0.9$ & $2.7 ;(2.2-3.1)$ & 0.8 \\
\hline
\end{tabular}


Table 4. Cytokine concentrations in the lymph of males and females at the age of 9 months.

\begin{tabular}{|c|c|c|c|c|c|}
\hline \multirow{2}{*}{$\begin{array}{c}\text { group of animals } \\
\text { cytokines }\end{array}$} & \multicolumn{2}{|c|}{$\begin{array}{l}\text { concentration of cytokine in the lymph of } \\
\text { females of nine months of age }\end{array}$} & \multicolumn{2}{|c|}{$\begin{array}{l}\text { concentration of cytokine in the lymph of } \\
\text { males of nine months of age }\end{array}$} & \multirow[b]{2}{*}{$\mathrm{p}$} \\
\hline & $\mathrm{M} \pm \sigma$ & Me; (LQ-HQ) & $\mathrm{M} \pm \sigma$ & Me; (LQ-HQ) & \\
\hline IL-1 $\alpha$ & $10.8 \pm 4.2$ & $12.3 ;(6.5-14.8)$ & $27.3 \pm 12.7$ & 24.9; (15.7 - 37.1) & 0.03 \\
\hline IL-1 $\beta$ & $261.9 \pm 111.7$ & 180.7; (176.7 - 367.3) & $151.7 \pm 59.6$ & $147.2 ;(98.2-202.3)$ & 0.3 \\
\hline IL-2 & $1301.8 \pm 695.6$ & 1354.5 (532. - 2058.0) & $722.6 \pm 580.8$ & 361.7; (243.5 - 1127.6) & 0.3 \\
\hline IL-4 & $10.7 \pm 4.9$ & $9.5 ;(5.8$ - 15.9) & $13.1 \pm 9.3$ & $9.5 ;(5.8-9.5)$ & 0.9 \\
\hline IL-6 & $2.9 \pm 1.7$ & $2.1 ;(1.5-4.2)$ & $4.9 \pm 1.4$ & 5.6; $(4.7-6.4)$ & 0.14 \\
\hline IL-10 & $253.8 \pm 120.7$ & 190.8; (149.3 - 73.8) & $233.1 \pm 75.9$ & 217.2; (177.1 - 283.2) & 1.0 \\
\hline GM-CSF & $82.9 \pm 95.9$ & 15.6; (8.7 - 174.0) & $10.5 \pm 4.6$ & $9.5 ;(6.1-9.5)$ & 0.2 \\
\hline $\operatorname{IFN} \gamma$ & $183.3 \pm 62.9$ & 152.4; (128.0 - 246.3) & $128.5 \pm 101.9$ & 89.2; (34.8 - 209.2) & 1.0 \\
\hline $\mathrm{TNF} \alpha$ & $2.4 \pm 1.0$ & $2.7 ;(1.3-3.2)$ & $2.7 \pm 0.9$ & $2.7 ;(2.2-3.1)$ & 1.0 \\
\hline
\end{tabular}

Table 5. Cytokine concentrations in the lymph and blood serum of males aged 3 months.

\begin{tabular}{|c|c|c|c|c|c|}
\hline \multirow{2}{*}{$\begin{array}{c}\text { Group of animals } \\
\text { cytokines }\end{array}$} & \multicolumn{2}{|c|}{$\begin{array}{l}\text { Concentration of cytokine in the lymph of } \\
\text { males of three months of age }\end{array}$} & \multicolumn{2}{|c|}{$\begin{array}{l}\text { Concentration of cytokine in the blood serum } \\
\text { of males of three months of age }\end{array}$} & \multirow[b]{2}{*}{$\mathrm{p}$} \\
\hline & $\mathrm{M} \pm \sigma$ & Me; (LQ-HQ) & $\mathrm{M} \pm \sigma$ & Me; (LQ-HQ) & \\
\hline IL-1 $\alpha$ & $10.9 \pm 6.3$ & $10.1 ;(4.6-16.4)$ & $4.3 \pm 1.7$ & 4.6; (3.3 - 6.4) & 0.09 \\
\hline IL- $1 \beta$ & $151.2 \pm 59.1$ & 148.5; (98.8 - 200.9) & $27.8 \pm 13.4$ & 27.8; (14.3 - 41.2) & 0.006 \\
\hline IL-2 & $979.4 \pm 349.8$ & 979.5; (662.5 - 1296.4) & $2.5 \pm 1.1$ & $2.1 ;(1.8-3.4)$ & 0.0007 \\
\hline IL-4 & $13.9 \pm 7.9$ & $18.1 ;(4.6-19.4)$ & $5.7 \pm 0.8$ & $6.4 ;(4.6-6.4)$ & 0.2 \\
\hline IL-6 & $4.2 \pm 1.6$ & $4.8 ;(3.7-5.3)$ & $2.8 \pm 1.2$ & $2.6 ;(1.8-4.1)$ & 0.07 \\
\hline IL-10 & $255.7 \pm 78.1$ & $223.7 ;(203.8$ - 275.6$)$ & $259.2 \pm 152.6$ & 259.2; (106.6 - 411.9) & 0.67 \\
\hline GM-CSF & $51.8 \pm 43.1$ & 46.6; (10.7 - 87.8) & $2.9 \pm 1.6$ & $2.6 ;(1.0-4.1)$ & 0.0006 \\
\hline $\operatorname{IFN} \gamma$ & $134.7 \pm 9.6$ & 139.6; (132.7 - 141.5) & $3.1 \pm 1.5$ & $2.8 ;(1.8-4.2)$ & 0.001 \\
\hline $\mathrm{TNF} \alpha$ & $2.7 \pm 1.2$ & $2.2 ;(1.9-3.5)$ & $3.1 \pm 1.5$ & $2.7 ;(1.8-4.3)$ & 0.9 \\
\hline
\end{tabular}

Table 6. Cytokine concentrations in the lymph and blood serum of males aged 9 months.

\begin{tabular}{|c|c|c|c|c|c|}
\hline \multirow{2}{*}{$\begin{array}{c}\text { Group of animals } \\
\text { cytokines }\end{array}$} & \multicolumn{2}{|c|}{$\begin{array}{l}\text { Concentration of cytokine in the blood serum } \\
\text { of males of nine months of age }\end{array}$} & \multicolumn{2}{|c|}{$\begin{array}{l}\text { Concentration of cytokine in the lymph of } \\
\text { males of nine months of age }\end{array}$} & \multirow[b]{2}{*}{$\mathrm{p}$} \\
\hline & $\mathrm{M} \pm \sigma$ & Me; (LQ-HQ) & $\mathrm{M} \pm \sigma$ & Me; (LQ-HQ) & \\
\hline IL-1 $\alpha$ & $3.6 \pm 1.8$ & $3.6 ;(1.8-5.0)$ & $27.3 \pm 12.7$ & 24.9; (15.7 - 37.1) & 0.001 \\
\hline $\mathrm{IL}-1 \beta$ & $2.8 \pm 1.4$ & $2.2 ;(1.8-3.5)$ & $151.7 \pm 59.6$ & 147.2; (98.2 - 202.3) & 0.003 \\
\hline IL-2 & $2.3 \pm 0.8$ & $2.1 ;(1.8-2.4)$ & $722.6 \pm 580.8$ & $361.7 ;(243.5$ - 1127.6) & 0.001 \\
\hline IL-4 & $9.4 \pm 3.0$ & $9.4 ;(6.4-12.4)$ & $13.1 \pm 9.3$ & $9.5 ;(5.8-9.5)$ & 0.6 \\
\hline IL-6 & $3.1 \pm 1.2$ & $2.6 ;(2.1-3.5)$ & $4.9 \pm 1.4$ & $5.6 ;(4.7-6.4)$ & 0.07 \\
\hline IL-10 & $59.0 \pm 16.8$ & 59.0; (42.2 - 75.8) & $233.1 \pm 75.9$ & 217.2; (177.1 - 283.2) & 0.06 \\
\hline GM-CSF & $2.6 \pm 1.3$ & $2.6 ;(1.0-4.1)$ & $10.5 \pm 4.6$ & $9.5 ;(6.1-9.5)$ & 0.001 \\
\hline $\mathrm{IFN} \gamma$ & $3.7 \pm 2.1$ & $3.6 ;(1.1-6.4)$ & $128.5 \pm 101.9$ & 89.2; (34.8 - 209.2) & 0.001 \\
\hline TNF $\alpha$ & $4.3 \pm 1.7$ & $4.4(2.9-6.4)$ & $2.7 \pm 0.9$ & $2.7 ;(2.2-3.1)$ & 0.1 \\
\hline
\end{tabular}


Table 7. Concentration of cytokines in the blood serum and lymph of females aged 9 months.

\begin{tabular}{|c|c|c|c|c|c|}
\hline \multirow{2}{*}{$\begin{array}{c}\text { Group of animals } \\
\text { cytokines }\end{array}$} & \multicolumn{2}{|c|}{$\begin{array}{l}\text { Concentration of cytokine in the blood serum } \\
\text { of females of nine months of age }\end{array}$} & \multicolumn{2}{|c|}{$\begin{array}{l}\text { Concentration of cytokine in the lymph of } \\
\text { females of nine months of age }\end{array}$} & \multirow[b]{2}{*}{$\mathrm{p}$} \\
\hline & $\mathrm{M} \pm \sigma$ & Me; (LQ-HQ) & $\mathrm{M} \pm \sigma$ & Me; (LQ-HQ) & \\
\hline $\mathrm{IL}-1 \alpha$ & $7.4 \pm 0.8$ & $6.9 ;(6.7-7.8)$ & $10.8 \pm 4.2$ & $12.3 ;(6.5-14.8)$ & 0.3 \\
\hline IL-1 $\beta$ & $50.6 \pm 4.0$ & 50.6; (46.6 - 54.6) & $261.9 \pm 111.7$ & $180.7 ;(176.7-367.3)$ & 0.001 \\
\hline IL-2 & $2.7 \pm 1.2$ & $2.7 ;(1.8-3.5)$ & $1301.8 \pm 695.6$ & 1354.5; (532. - 2058.0) & 0.001 \\
\hline IL-4 & $2.7 \pm 1.0$ & $2.2 ;(2.1-3.4)$ & $10.7 \pm 4.9$ & 9.5; (5.8 - 15.9) & 0.004 \\
\hline IL-6 & $2.8 \pm 1.0$ & $2.2 ;(2.1-3.4)$ & $2.9 \pm 1.7$ & $2.1 ;(1.5-4.2)$ & 0.72 \\
\hline IL-10 & $121.2 \pm 14.6$ & 121.2; (106.6 - 135.8) & $253.8 \pm 120.7$ & 190.8; (149. - 373.8) & 1.0 \\
\hline GM-CSF & $2.6 \pm 1.1$ & 2.6; (1.8 - 3.4) & 82.995 .9 & 15.6; (8.7 - 174.0) & 0.001 \\
\hline $\mathrm{IFN} \gamma$ & $3.4 \pm 1.5$ & $3.6 ;(1.9-4.6)$ & $183.3 \pm 62.9$ & $152.4 ;(128.0$ - 246.3) & 0.001 \\
\hline $\mathrm{TNF} \alpha$ & $3.5 \pm 1.3$ & $3.2 ;(2.1-4.3)$ & $2.4 \pm 1.0$ & $2.7 ;(1.3-3.2)$ & 0.3 \\
\hline
\end{tabular}

found such differences. In the group of older animals [4] we have not found such differences. In some studies, the content of the anti-inflammatory cytokine IL-10 did not change, and TGF was significantly increased in the group of elderly animals [5]. We found gender differences in the cytokine profiles of lymph; other authors have also found such differences. [5]. It is likely that the role of various cytokines is shown at different stages of development of the lymph and lymphatic systems. It can be assumed that some cytokines, such as GM-CSF, regulate the differentiation and proliferation of granulocytes, and macrophages regulate the proliferation and differentiation of cells belonging to different germs' hematopoiesis [6]. Accordingly, the levels of cytokines at different stages of development of lymphoid cells are different. Attention to the study of the lymphatic system and the cellular composition of the lymph is due to the reason that it, being one of the main links of homeostasis and humoral transport, is involved in all pathological processes, regardless of their etiology and pathogenesis. It should be noted that one of the basic properties of the lymph and the blood, characterizing their rheological characteristics, is that viscosity flows from the peripheral lymph, which may vary with inappropriate lymph formation and depends on several factors-shaped elastic elements, $\mathrm{pH}$, temperature, the amount of formed elements in the plasma. Rheological properties are also characterized by all sorts of lymph changes in plasma viscosity and lymph composition of its proteins. Some cytokines in blood plasma and lymph can be associated with carrier proteins and various inhibitors, thus the cytokines do not have biological activity, but can be detected immunochemically using specific antibodies. Determination of cytokine levels in the lymph and blood serum has a number of difficulties due to non-specific binding factors, which are different serum proteins. The presence of low levels of cytokines in the lymph and blood plasma of healthy donors could be explained by the fact that they can appear in the circulation as a result of certain normal physiological processes of living organisms, the organism during ontogeny or the influenced stressors' infectious nature. In some cases, these cytokine levels are a manifestation of a hidden smoldering inflammation. All cytokines exist as soluble forms and are secreted extra-cellularly in an active form, but some of them are able to covalently bind and form complexes with cell membranes. In such form, for example, there exist IL-1 and TNF. Cytokines are hormone-like molecules (in the biological action) with a short lifetime, endowed with functions, and they provide signaling cell integration, growth regulation, differentiation, survival and apoptosis. They are distinguished from hormones in that they are synthesized and secreted by a variety of cell types that, accordingly, control all their diversity. Cytokines possess not only endocrine, but also much more pronounced autocrine and paracrine activity, which may be mediated by second messengers such as prostaglandin E2 [7]. They not only have endocrine, but much more pronounced autocrine and paracrine activity. In an immune response involving both pro-inflammatory and anti-inflammatory cytokines, their amounts are defined in equilibrium. In particular, substantial excess drawback inflammatory or anti-inflammatory cytokines can cause chronic inflammation. The unidirectional nature of the action of cytokines is multiplying, multi-directional and balanced. Thus, they induce synthesis cascaded to each other and transmodulate surface receptors to each other. The production of cytokines is a marker of differentiation, of pro- 
liferation of certain cell types. If predominate, IL-4 T-lymphocytes are T-helper cells and begin to synthesize IL-4, 5, 6, 7, 10. These last activate proliferation of B lymphocytes with respective immunoglobulin synthesis. If predominate, e.g., IL-10, the synthesis of inflammatory cytokines is inhibited. Because of this, IL-10 was called an anti-inflammatory. Elderly animals are more susceptible to bacterial and viral infections and neoplasia than younger adults. This is associated with impaired immune responsiveness, and decreased production of interleukin (IL)-2 and soluble interleukin-2 receptors (SIL-2R). Nevertheless, IL-2R expressions on the cell surface are normal. Interferon (IFN)-gamma, as the main helper T-1 (Th1), is a cytokine that produced fewer lymphocytes in the elderly, while TH2 cytokines IL-4 and IL-10 are produced in large amounts compared with the stimulated lymphocytes of young donors. The decrease of IFN-gamma correlated with the decrease in the number of CD45RO+/CD8+ T-cells. Therefore, in the elderly, there is a violation of the regulation in TH1/TH2 and the dominance function TH2. Monocyte function increased in the elderly. Leukocytes in the elderly produce higher amounts of IL-1, IL-6, IL-8 and the tumor necrosis factor (TNF)-alpha after induction with lipopolysaccharide (LPS), than leukocytes of young donors. In contrast, in vitro induction of IFN-alpha influenced virus is reduced in the elderly compared to the young [8]. Cytokine levels in blood plasma and the lymph reflect the current state of development and different populations (and sub-) cells of defense reactions, i.e., cytokine synthesis by cells of an organism in vivo. Determination of levels of cytokine production by cells isolated in vitro shows the functional state of the cells. Spontaneous cytokine production in culture indicates that the cells are activated in vivo or by teaching manipulation cells in vitro. This induced production of cytokines to evaluate the potential of cell activation, which is important to evaluate the immunological reactivity. Reduced induced cytokine production in vitro may be one of the signs of immunodeficiency. So both options, studying cytokine levels in the circulation or production cells, are important in terms of the characteristics of the functional activity of cells.

\section{Conclusion}

1. We found age and gender differences between the concentration of pro- and anti-inflammatory cytokines in the lymph and blood serum. 2. A comparative study of the cytokine profile of the lymph and blood in Wistar rats showed that the concentration of cytokine in the lymph was significantly higher compared to the blood serum.

\section{References}

[1] Poveshchenko, O., Kolesnikov, A., Kim, I., Ulyanov, E., Mozzherina, A., Jankajte, E., Solovieva, A., Herter, T., Poveshchenko, A. and Konenkov, V. ( 2008 ) Methods for Isolating and Culturing Conditions Mesenchymal Stromal Cells from Human Adipose Tissue Obtained from Various Sources. Bulletin of RAMS, 133, 90-95.

[2] Poveshchenko, A., Abramov, V. and Kozlov, V. (2007) Cytokines-Factors Neuroendocrine Regulation. Advances of Physiological Sciences, 3, 40-46.

[3] Kuznetsov, A. (1993) A New Way of Sampling Lymph Animals. Bulletin of Experimental Biology and Medicin, 116, 329-331.

[4] Xin, D., Harris, M., Wade, K., Amin, M., Barr, A. and Barbe, M. (2011) Aging Enhances Serum Cytokine Response but Not Task-Induced Grip Strength Declines in a Rat Model of Work-Related Musculoskeletal Disorders. BMC Musculoskeletal Disorders, 12, 63. http://dx.doi.org/10.1186/1471-2474-12-63

[5] Forsey, R., Thompson, J., Ernerudh, J., et al. (2003) Plasma Cytokine Profiles in Elderly Humans. Mechanisms of Ageing and Development, 124, 487-493. http://dx.doi.org/10.1016/S0047-6374(03)00025-3

[6] Cecchini, G., Dominguez, M., Mocci, S., Wetterwald, A., Felix, R., Fleisch, H., Chisholm, O., Hofstetter, W., Pollard, J. and Stanley, R. (1994) Role of Colony Stimulating Factor-1 in the Establishment and Regulation of Tissue Macrophages during Postnatal Development of the Mouse. Development, 120, 1357-1372.

[7] Kozlov, V., Poveshchenko, A. and Gromykhina, N. (1990) Some Mechanisms Involved in the Prostaglandin E2 Immunosuppressive Effect in (CBA X C57BL) F1 Mice in Vivo. Cellular Immunology, 128, 242-249. http://dx.doi.org/10.1016/0008-8749(90)90022-J

[8] Rink, L., Cakman, I. and Kirchner H. (1998) Altered Cytokine Production in the Elderly. Mechanisms of Ageing and Development, 102, 199-209. http://dx.doi.org/10.1016/S0047-6374(97)00153-X 
Scientific Research Publishing (SCIRP) is one of the largest Open Access journal publishers. It is currently publishing more than 200 open access, online, peer-reviewed journals covering a wide range of academic disciplines. SCIRP serves the worldwide academic communities and contributes to the progress and application of science with its publication.

Other selected journals from SCIRP are listed as below. Submit your manuscript to us via either submit@scirp.org or Online Submission Portal.
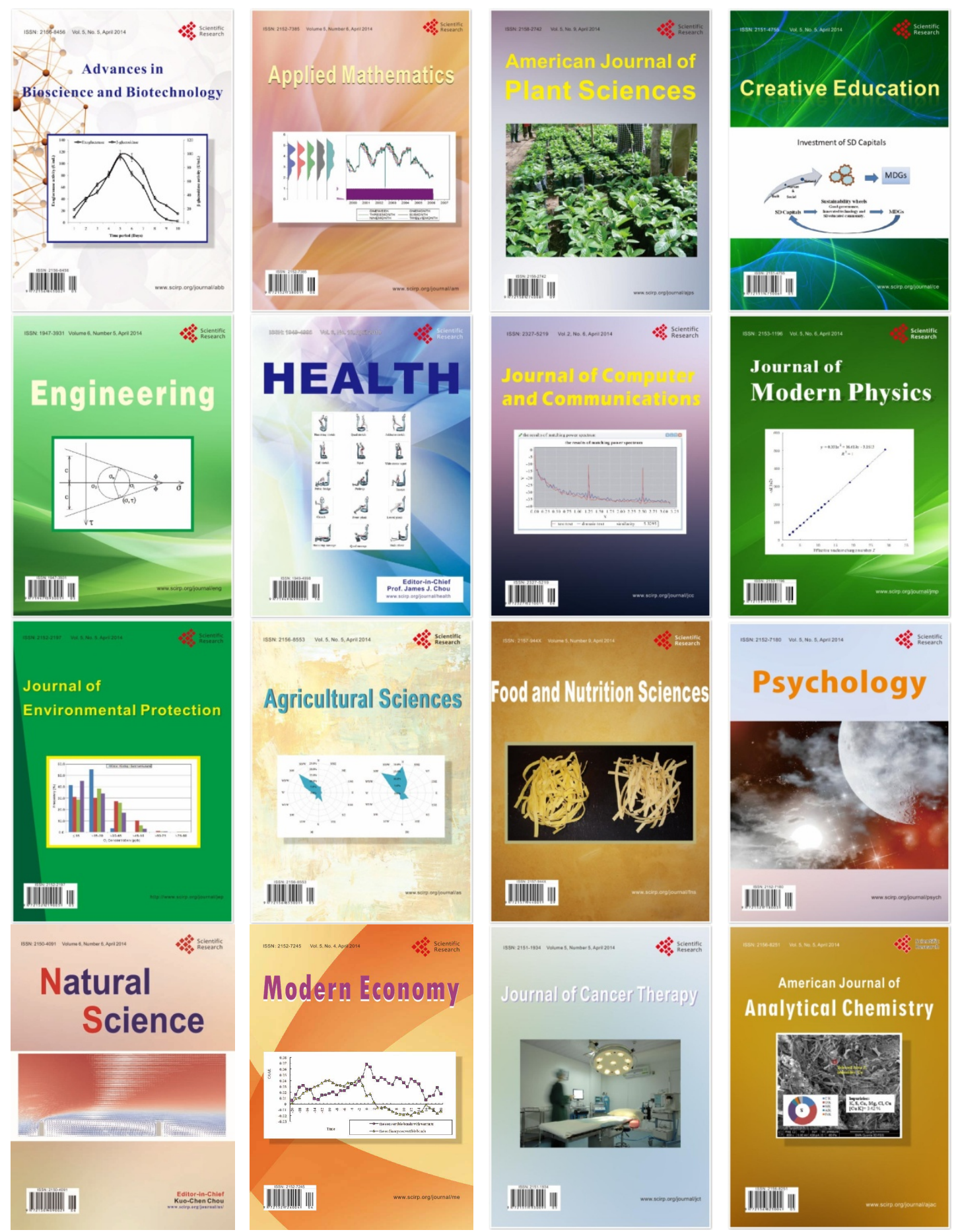